\title{
Psychiatry and Primary Care
}

Recent epidemiologic studies have found that most patients with mental illness are seen exclusively in primary care medicine. These patients often present with medically unexplained somatic symptoms and utilize at least twice as many health care visits as controls. There has been an exponential growth in studies in this interface between primary care and psychiatry in the last 10 years. This special section, edited by Wayne J. Katon, M.D., will publish informative research articles that address primary care--psychiatric issues.

\section{Prevalence, Nature, and Comorbidity of Depressive Disorders in Primary Care}

\author{
James C. Coyne, Ph.D., Suzanne Fechner-Bates, Ph.D., and \\ Thomas L. Schwenk, M.D.
}

\begin{abstract}
This article examines the prevalence, nature, and comorbidity of depressive disorders using DSM-III-R criteria among patients recruited from the waiting rooms of family physicians. A total of 1928 family practice patients completed a screening form including the Center for Epidemiologic Studies-Depression Scale (CES-D), and patients with elevated $C E S-D$ scores were oversampled for possible interviews using the Structured Clinical Interview for the DSM-III-R (SCID). In the resulting weighted sample of 425 , a prevalence of $13.5 \%$ was obtained for major depression and $22.6 \%$ for all depressive disorders. Over $40 \%$ of the patients with major depressive disorder (MDD) were only mildly depressed. Gender and other demographic variables failed to distinguish depressed patients, but a variety of self-ratings did. Depression was associated with comorbid anxiety disorders and substance abuse. Results are discussed in terms of the implications of depression in primary care as a public health problem, but also in terms of some diagnostic issues, particularly the use of an impairment criterion for major depression.
\end{abstract}

\section{Introduction}

Whereas only $20 \%$ of community residents with major depression are seen by mental health practitioners, over half are seen in primary medical care settings [1]; yet $50 \%-70 \%$ of them go unde-

Department of Family Practice, The Universily of Michigan Medical Center, Ann Arbor, Michigan

Address reprint requests to: James C. Coyne, Ph.D., Department of Family Practice, University of Michigan Medical Center, Ann Arbor, MI 48109-0118. tected by their physicians [2-5]. The prevalence of major depression among primary care patients appears to be considerably higher than the $2.7 \%$ found in samples drawn directly from the community [6]. Past research has varied in the assessment procedures, diagnostic criteria, and particular populations studied, but they have yielded estimates of the prevalence of major depression from $4.8 \%$ to $8.6 \%$ among primary care patients $[4,7-11]$. The lower estimates may still make major depression the most common condition in primary care, perhaps exceeding even hypertension [7]. Milder forms of depression not meeting full criteria for major depression are also common $[7,12]$. Estimates of the rates of dysthymia or minor and intermittent depression among primary care patients range from an additional $2 \%-9 \%[11,13,14]$.

In addition to establishing the prevalence rates of depressive disorders in primary care, it is important to develop a more refined picture of their nature and severity. It has been suggested that undetected depression in primary care is a major public health problem [15]. Furthermore, strategies for improving the management of depressed primary care patients have assumed some comparability between them and the more extensively studied depressed psychiatric patients. However, the validity of such assumptions remains to be demonstrated in more detailed study of depressed patients in primary care [16].

Available data are still limited, but it has been 
suggested that there is conspicuous psychiatric morbidity among primary care patients $[12,17]$ but that much of the depression is mild and selflimiting $[7,18,19]$. There have also been indications of a high prevalence of mixed anxiety-depression conditions among primary care patients $[4,13,14]$.

The present study explored the prevalence and nature of depressive disorders among family practice patients, including psychiatric comorbidity, using a two-stage selection and assessment procedure involving the Center for Epidemiologic Studies-Depression Scale (CES-D) [20] and the Structured Clinical Interview for the DSM-III-R (SCID)[21]. Family practice patients were screened in their physician's waiting rooms, and patients scoring above an established cutpoint on the CES-D were oversampled in making selections for the diagnostic interview. Rates of psychiatric diagnoses obtained in the interview were then adjusted for the oversampling procedure. Such twostaged selection strategies are an efficient means of studying prevalence when an economical screening instrument is available that has good sensitivity, even if poorer specificity [22]. The CES-D is suitable for this purpose [23]. Two-staged strategies actually yield more accurate estimates of prevalence than when the same number of diagnostic interviews is obtained from a full population [24].

In interpreting the results of the present study, it will be important to keep in mind the particular structured interview and diagnostic criteria that were employed. The SCID differs from other interview schedules that have been used to diagnose depression among primary care patients. It supersedes the Schedule of Affective Disorders and Schizophrenia (SADS) [25] which employed Research Diagnostic Criteria (RDC) [26]. In the RDC, a diagnosis of major depression required a minimum of 2 weeks of mood disturbance, five depressive symptoms in addition to mood disturbance, and impairment as represented by seeking of treatment or interference with social roles. The RDC also employed a hierarchical rule that limited the diagnosis of a current anxiety disorder when a depressive disorder is present. If a person experienced symptoms of anxiety only during a depressive episode, only the depressive episode would be diagnosed. The SCID provides for DSM-III-R [27] diagnoses. DSM-III-R requires 2 weeks of mood disturbance and at least five depressive symptoms including mood disturbance for the diagnosis of major depression, and there is no requirement of impairment. The hierarchical rule for diagnosing anxiety disorders in the presence of depression was also relaxed in DSM-III-R, allowing for greater comorbidity of depression and anxiety. Finally, the inclusion of Adjustment Disorder with Depressed Mood and Adjustment Disorder with Mixed Mood allows for diagnosis of some depressive conditions which would be too mild and transient to obtain a diagnosis with RDC.

The Diagnostic Interview Schedule (DIS) [28] can be used for assignment of DSM-III- $R$ diagnoses, and it has become the most widely used research tool for diagnosing depression in primary care by interview. Whereas the SCID employs trained mental health professionals as interviewers, the DIS employs lay interviewers. Because of a lack of confidence in the ability of lay persons to judge the presence of mild symptoms in a nonpsychiatric population, diagnosis of major depression based on results of a DIS interview routinely requires respondents to meet an additional impairment criterion [29]. Finally, with few exceptions [4], most applications of it in primary care have relied on DSM-III criteria [30] which, like the RDC, included a hierarchical rule excluding diagnosis of an anxiety disorder confined in duration to a concurrent major depression.

These are not merely technical or methodological points. To our knowledge, the present study is the first to utilize the SCID to examine the full range of DSM-III-R depressive disorders in a primary care population as assessed by trained mental health professionals. The prevalence, severity, and correlates of depression which were found may differ from past studies, particularly because of the dropping of the impairment criterion and greater allowance for anxiety-depression comorbidity. Results are relevant to appraisal of the public health problem posed by undetected depression in primary care and evaluation of recommendations for improving detection, diagnosis, and treatment. Yet, these results may also reflect on the clinical utility of unmodified DSM-III-R criteria within the context of primary care $[3,16]$. Notably, DSM-III-R criteria were developed and validated mainly in psychiatric settings in which patients meet an impairment criteria by virtue of their having sought help. In contrast, most depressed primary care patients are not seeking treatment for depression in their index visit to their physician, and application of unmodified DSM-III-R criteria in this setting may identify a group of patients who are distinctly different from depressed psychiatric patients and for whom recommendations based on 
research in psychiatric settings may be less appropriate.

\section{Method}

The data reported here are derived from a larger project comparing depression among family practice patients to what is presented in an outpatient depression program based in a university department of psychiatry [2]. Patients enrolled in this study were recruited from the practices of 50 family physicians in what are primarily rural and suburban areas of southeastern Michigan.

In the physicians' waiting rooms, patients completed a screening form which included the CES-D and a number of demographic questions and selfratings. The self-ratings included primary and secondary reasons for visit; reports of appetite, sleep, and energy levels; and 7-point measures of stress and mood. Based on CES-D scores, a subsample of patients was selected for a possible structured interview by a trained psychiatric social worker or masters level mental health professional and subsequent follow-up. A total of 1928 patients completed the screening.

Two considerations shaped the sampling strategy for screened patients selected to receive a SCID interview in this study. First, we sought to follow a sample of approximately equal numbers of family practice patients who had a current depressive diagnosis and those who did not. Because the CES-D has good sensitivity but poor specificity [23], there could be some confidence that patients with low scores were not depressed, but most patients with high scores were also not depressed $[32,33]$. Therefore, we oversampled patients with high scores. Second, concerns about both the temporal instability of patients' scores on the CES-D and about the need to match the time period covered by CES-D and the SCID led to a decision to impose a 2-week limit on the time between the screening and the interview. Although respectable reliability coefficients have been reported for the CES-D, the stability of high scores is considerably lower than one would expect from such figures [34]; elevated scores may drop substantially in weeks [35] or even hours [36]. Furthermore, instructions for the CES-D indicate that responses to questions should refer to the past week, whereas current status as assessed by the SCID covers the last month. To insure an overlap between the periods covered by the two measures, the SCID must thus be administered within 3 weeks of the screen- ing. In this study, the more stringent limitation of 2 weeks was adopted in order to capture more accurately the status of patients at the time of their visit to the physician. Taking these considerations together, the resulting strategy involved oversampling patients meeting the standard cutpoint of 16 on the CES-D, and limiting diagnostic interviews to patients who could be scheduled within 2 weeks. Of the 1928 patients screened in the physicians' waiting rooms, $1254(65.0 \%)$ obtained a low score on the CES-D $(<16)$. From this group, 620 were targeted for possible administration of the SCID. Of the targeted group, $154(24.8 \%)$ received the SCID; $212(34.2 \%)$ refused the SCID at the point of screening, $56(9.0 \%)$ refused participation when contacted by an interviewer, 81 (13.1\%) lived out of the geographical area or could not be contacted by telephone, and $117(18.9 \%)$ could not be scheduled within the designated time period. In the screened sample, $674(35.0 \%)$ of the patients scored at or above the CES-D cutpoint. Of them, $271(40.2 \%)$ received the SCID, $101(15.0 \%)$ refused the SCID at the point of screening, $53(7.9 \%)$ refused the SCID when contacted by an interviewer, $72(10.7 \%)$ lived out of the geographical area or could not be contacted by telephone, and 117 (17.3\%) could not be scheduled within the designated time period.

Administration of the SCID was audiotaped with the patients' consent, and a subset of the tapes were used to determine the reliability of interviewer judgments. Interrater reliability was high: $97 \%$ for rating of symptom levels and $93 \%$ for diagnostic decisions. In addition to making a DSMIII-R diagnosis, interviewers completed the semistructured interview version of the Hamilton Rating Scale for Depression [37,38]. Interrater reliability for the Hamilton was 0.89 .

\section{Results}

\section{Analysis of Sampling Bias}

Use of a two-staged selection procedure necessitates a weighting procedure to compensate for the oversampling of patients more likely to have a disorder [39]. However, an additional question is whether the transition from completion of a screening instrument to acceptance and completion of a diagnostic interview introduces a selective loss of subjects and systematic biases in subsequent findings. With few exceptions [40], studies of psychiatric disorders in primary care have either 
simply noted such a problem and speculated about its effects or ignored it. The issue can be addressed by examination of differences in screening data for patients receiving a SCID $\mathrm{v}$ those who did not. For patients scoring below the cutpoint on the CES-D, few differences were found when we examined the full range of demographic variables, total and individual item scores on the CES-D, and the various patient self-rating scales on the screening questionnaire. Patients receiving a SCID had reported more physician visits in the past year, $\chi^{2}(2)$ $=7.89, p<0.05$, were somewhat less likely to be currently working, $\chi^{2}(1)=4.37, p<0.05$, and were slightly younger, $t(1241)=2.02, p<0.05$.

A similar pattern of few differences was found for patients with CES-D scores above the cutpoint who received a SCID versus those who did not. Those receiving a SCID were more likely to endorse acute problems as their reason for a visit, and were more likely to have a psychological complaint for a secondary reason for a visit, $\chi^{2}(2)=$ $6.70, p<0.05$. They also had fewer children under age $6, t(328)=2.00, p<0.05$.

\section{Estimated Prevalence of Depressive Disorders}

Table 1 presents the raw and weighted breakdown of depressive disorders identified in the two-stage selection and diagnosis procedure. To obtain weighted estimates of prevalence, patients were stratified according to whether they scored below the cutpoint on the CES-D, and weights were assigned according to the proportion of screened patients receiving a SCID. These weights were then used to adjust the observed number of patients in each stratum diagnosed with major depressive disorder (MDD), any depressive disorder, or a psychiatric diagnosis other than depression in the interviews. For major depression, a weighted, estimated prevalence of $13.5 \%(\mathrm{SE}=0.9)$ was obtained. For all depressive disorders, a weighted, estimated prevalence of $22.6 \%(\mathrm{SE}=1.1)$ was obtained. Thus, little more than half of the depressed patients met criteria for unipolar MDD, and even if we count patients with bipolar disorder as MDD, we still find that over a third of the depressed patients fail to meet criteria for MDD.

\section{Nature and Correlates of Depressive Disorders}

Severity of MDD. Table 2 gives the breakdown of the patients with MDD according to severity as assessed by DSM-III-R criteria as well as the mean Hamilton scores for each of the categories. According to DSM-III-R, the category "mild" designates patients with major depressive disorder who have few, if any, symptoms in excess of what was needed for a diagnosis and only minor impairment in their social roles; "moderate" designates patients with symptoms or impairment falling between "mild" and "severe"; and the "severe" category indicates several symptoms in excess of

Table 1. Depressive diagnoses in the weighted and unweighted sample

\begin{tabular}{lccc}
\hline \multicolumn{1}{c}{ SCID diagnosis } & $\begin{array}{c}\text { Unweighted } \\
\text { sample }\end{array}$ & $\begin{array}{c}\text { Weighted } \\
\text { sample }\end{array}$ & $\begin{array}{c}\text { Estimated } \\
\text { prevalence }\end{array}$ \\
\hline All major depression & $\mathrm{N}$ & $\mathrm{N}$ & \\
$\quad$ Major depression only & 91 & 57 & $13.5 \%$ \\
Double depression & 80 & 51 & \\
Bipolar I, depressed & 2 & 1 & \\
Bipolar II, depressed & 3 & 2 & \\
Bipolar I, mixed & 6 & 3 & \\
Bipolar II, mixed & 4 & 2 & \\
Dysthymia & 2 & 2 & \\
Adjustment disorder & 17 & 9 & \\
$\quad$ with depressed or & & & \\
mixed mood & 20 & 18 & \\
Depression, NOS & 0 & 0 & \\
Uncomplicated bereavement & 7 & 6 & \\
Organic mood disorder & 0 & 0 & \\
Total depressive disorders & 141 & 94 & $22.0 \%$ \\
\hline
\end{tabular}


Table 2. Severity of major depression

\begin{tabular}{|c|c|c|c|}
\hline & Mild & Moderate & Severe \\
\hline Number & $(44.5 \%)$ & $(37.9 \%)$ & $(17.6 \%)$ \\
\hline \multicolumn{4}{|l|}{ Mean 17-item } \\
\hline Hamilton Score & $10.42(6.17)$ & $13.43(7.24)$ & $17.04(5.06)$ \\
\hline
\end{tabular}

Note: Data missing for one subject.

what was required for a diagnosis and marked interference with occupational functioning or usual social involvements. DSM-III- $R$ distinguishes whether severe MDD is associated with psychotic features, but for the purposes of our analyses, we lumped the 1 patient with psychotic features with the other patients with severe MDD. As can be seen, the largest group of patients, over $40 \%$, were only mildly depressed in terms of severity of symptoms and impairment. Indeed, the estimated prevalence of MDD of at least moderate severity was only $7.5 \%(\mathrm{SE}=0.7)$.

Demographic Variables. Table 3 provides comparisons of three groups of patients: those with MDD, those with other depressive disorders, and those without a depressive diagnosis. Starting with demographic variables, we note that there were no differences among the three groups in terms of gender, age, or marital status. The absence of a gender difference in depression is noteworthy. Although most depressed patients were female, that was true of the sample in general.

Self-Ratings. In contrast to the null finding with respect to demographic variables, self-ratings on the screening questionnaire strongly distinguished between the MDD patients and all others, as well as between the patients with other depressive diagnoses and the nondepressed patients. Notably, the MDD group reported being more depressed and having more stress, and a greater proportion of them rated themselves as having less energy, often feeling worn out, and having sleep and appetite disturbances. The patients with other depressive diagnoses were distinguished from nondepressed patients by higher self-ratings of depression and stress and more frequent en-

Table 3. Demographic and clinical features in weighted sample

\begin{tabular}{|c|c|c|c|c|c|}
\hline & \multicolumn{2}{|c|}{$\begin{array}{l}\text { Major depression } \\
\qquad N=58\end{array}$} & \multicolumn{2}{|c|}{$\begin{array}{l}\text { Other depressed } \\
\qquad N=39\end{array}$} & $\begin{array}{l}\text { Not depressed } \\
\qquad N=329\end{array}$ \\
\hline Percent female & $79.8 \%$ & & $76.1 \%$ & & $74.0 \%$ \\
\hline Percent white & $97.1 \%$ & & $95.5 \%$ & & $96.9 \%$ \\
\hline Age & 39.10 & $(12.97)$ & 39.73 & (16.77) & $40.95 \quad(14.68)$ \\
\hline Percent currently married & $74.0 \%$ & & $67.4 \%$ & & $78.5 \%$ \\
\hline Hamilton rating & 12.88 & $(6.9)^{* * *}$ & 7.98 & $(5.2)^{* * *}$ & $3.83(3.79)$ \\
\hline Global functioning & 60.36 & $(9.5)^{* * *}$ & 66.78 & $(10.1)^{* * *}$ & $79.66(8.85)$ \\
\hline CES-D & 26.02 & $(12.1)^{* * *}$ & 20.60 & $(11.8)^{* * *}$ & $10.85(8.0)$ \\
\hline Percent lifetime $\mathrm{Tx}$ & \multicolumn{2}{|c|}{$68.6 \% * * *$} & \multicolumn{2}{|c|}{$51.2 \%$} & $42.8 \%$ \\
\hline Hospitalizations & 0.21 & $(.50)^{*}$ & 0.13 & $(.64)$ & $0.06(.35)$ \\
\hline \multicolumn{6}{|l|}{ Patient ratings of } \\
\hline Stress & 5.89 & $(1.24)^{* * *}$ & 5.50 & $(1.75)^{* * *}$ & $4.58 \quad(1.49)$ \\
\hline Depression & 4.64 & $(1.65)^{* * *}$ & 4.06 & $(1.83)^{* * *}$ & $2.87(1.61)$ \\
\hline Much less energy & \multicolumn{2}{|c|}{$26.3 \% * * *$} & \multicolumn{2}{|c|}{$5.7 \%$} & $3.3 \%$ \\
\hline Often worn out & \multicolumn{2}{|c|}{$60.7 \%^{* * *}$} & \multicolumn{2}{|c|}{$40.5 \%$} & $29.4 \%$ \\
\hline Sleep ( 6 hours or less) & \multicolumn{2}{|c|}{$51.7 \% * * *$} & \multicolumn{2}{|c|}{$33.9 \%^{\top}$} & $24.5 \%$ \\
\hline Appetite disturbance & \multicolumn{2}{|c|}{$18.3 \%^{* * *}$} & \multicolumn{2}{|c|}{$22.1 \%^{* * *}$} & $2.9 \%$ \\
\hline
\end{tabular}

For MDD patients, significance levels refer to comparisons between the MDD patients and all others. For other depressed patients, significance levels refer to comparisons between them and nondepressed patients.

${ }^{\tau} p<0.10 ;{ }^{*} p<0.05 ;{ }^{* *} p<0.01 ;{ }^{* * *} p<0.001$. 
dorsement of having less energy and appetite disturbance.

Clinical Variables. The MDD patients were also distinguished from other patients in terms of a full range of clinical variables, and the patients with other depressive diagnoses were similarly distinguished from nondepressed patients. Specifically, MDD patients were distinguished by scores on the self-report CES-D, interviewer assessment on the Hamilton Depression Rating Scale, interviewer ratings of global functioning, and patient reports of previous treatment and hospitalizations. This is a rather consistent pattern of differences. However, examination of mean scores on these standardized measures indicates that even the MDD patients in our sample were relatively mildly depressed and high functioning. This is consistent with our earlier finding that the largest group of MDD patients had only mild severity according to DSM-III-R criteria. Patients with other depressive diagnoses differed from nondepressed patients in terms of CESD, Hamilton Rating Scale, and Global Assessment scores and past mental health treatment, but not hospitalizations.

Psychiatric Comorbidity. There was a high rate of lifetime psychiatric comorbidity for the patients with MDD (Table 4). Notably, over $40 \%$ of them had lifetime histories of anxiety disorder and over $40 \%$ similarly had histories of substance abuse, which in each instance was significantly higher than for nondepressed patients. Over a quarter met criteria for current anxiety disorders which is also significantly higher than for nondepressed patients. The patients with depressive disorders other than MDD differed from the nondepressed patients only in having greater lifetime comorbidity for anxiety disorders, $\chi^{2}(1)=4.44, p<0.05$ and substance abuse, $\chi^{2}(1)=4.16, p<0.05$. However, the excess of current substance abuse over what was found among nondepressed patients approached significance, $\chi^{2}(1)=3.51, p=0.06$.

\section{Discussion}

This study examined depressive disorders among family practice patients using unmodified DSMIII-R criteria as assessed by the SCID, a structured interview administered by a trained masters level interviewer. Our results can be discussed in terms of the prevalence, nature, correlates, and comorbidity of DSM-III-R depressive disorders in pri-
Table 4. Comorbidity of depression and other psychiatric disorders in a weighted sample

\begin{tabular}{|c|c|c|c|}
\hline $\begin{array}{l}\text { Comorbid } \\
\text { disorders }\end{array}$ & $\begin{array}{c}\text { MDD } \\
(N=58)\end{array}$ & $\begin{array}{c}\text { Other } \\
\text { depressed } \\
(N=39)\end{array}$ & $\begin{array}{c}\text { Not } \\
\text { depressed } \\
(N=329)\end{array}$ \\
\hline Current anxiety & $\begin{array}{l}16^{* * *} \\
(28.0 \%)\end{array}$ & $\begin{array}{c}6 \\
(16.0 \%)\end{array}$ & $\begin{array}{l}39 \\
(12.0 \%)\end{array}$ \\
\hline Lifetime anxiety & $\begin{array}{l}25^{* * *} \\
(44.1 \%)\end{array}$ & $\begin{array}{l}13 \\
(33.8 \%)\end{array}$ & $\begin{array}{l}64 \\
(19.3 \%)\end{array}$ \\
\hline $\begin{array}{l}\text { Current substance } \\
\text { abuse }\end{array}$ & $\begin{array}{l}3 \\
(5.7 \%)\end{array}$ & $\begin{array}{l}3 \\
(8.9 \%)\end{array}$ & $\begin{array}{l}10 \\
(3.0 \%)\end{array}$ \\
\hline $\begin{array}{l}\text { Lifetime substance } \\
\text { abuse }\end{array}$ & $\begin{array}{l}24 \\
(42.6 \%)\end{array}$ & $\begin{array}{l}18^{*} \\
(47.7 \%)\end{array}$ & $\begin{array}{l}104 \\
(31.5 \%)\end{array}$ \\
\hline $\begin{array}{l}\text { Current } \\
\text { somatization }\end{array}$ & $\begin{array}{l}2 \\
(2.9 \%)\end{array}$ & $\begin{array}{l}1 \\
(2.8 \%)\end{array}$ & $\begin{array}{l}3 \\
(0.9 \%)\end{array}$ \\
\hline
\end{tabular}

${ }^{*} p \leqslant 0.05 ;{ }^{* * *} p \leqslant 0.001$

mary care. Yet, rather than uncritically accepting the DSM-III-R diagnostic criteria as the "gold standard," we can also utilize our results to evaluate the appropriateness of these criteria for primary care [16].

To summarize our findings, more than one in eight family practice patients met criteria for MDD, and overall, a fifth of the patients recruited met criteria for some depressive disorder, if one includes uncomplicated bereavement which would have been diagnosed as MDD on the basis of symptomatology alone. However, over $40 \%$ of the patients with MDD had few or no symptoms beyond what is needed to meet criteria, and as seen in global assessment of functioning scores, they were not substantially impaired. Demographic variables did not distinguish between the depressed and nondepressed patients, and, in particular, men in this sample were no less likely to be depressed than women. As in another recent study [41], the excess of depressed females occurred because females were more likely to be found in the waiting room of a family physician.

Self-ratings of stress, depression, and reports of vegetative symptoms on a screening form distinguished between depressed and nondepressed patients. The same was true for CES-D scores, interviewer ratings of depressive symptomatology and global functioning, and patient reports of past mental health treatment. Nonetheless, such clini- 
cal findings are congruent with the ratings of severity according to DSM-III-R in indicating that much of the depression in primary care is relatively mild and not associated with substantial impairment.

Our findings thus indicate that depressive disorders diagnosed according to DSM-III-R are highly prevalent and yet relatively mild in primary care. Our estimates of prevalence are substantially higher than what was found in past studies $[4,7-$ 11], but we may be among the first to apply unmodified DSM-III-R criteria to a primary care population. Unlike past studies, we thus did not require for a diagnosis of MDD that a patient had sought help, taken medication, or suffered impairment in role functioning, and this may account for both the higher prevalence and relative mildness of the depression that we found. If we count only cases of major depression with at least moderate severity, our estimated prevalence is more in line with past studies.

There was substantial psychiatric comorbiditynotably current and lifetime anxiety disorders and lifetime substance abuse-among patients diagnosed with MDD. With the hierarchical rule for diagnosing anxiety disorders having been relaxed in DSM-III-R, a quarter of the patients with MDD were also diagnosed as currently having an anxiety disorder. However, we should note that whereas DSM-III-R allows for diagnosis of a panic disorder, agoraphobia, social or simple phobia, or obsessivecompulsive disorders in a patient with a concurrent mood disorder, it still does not allow for diagnosis of a generalized anxiety disorder (GAD) when the anxiety is limited to the course of a mood disorder. Furthermore, the SCID assesses only current, not past anxiety disorders, and the GAD module is simply skipped if the patient has a current mood disorder. This feature of the SCID is particularly unfortunate for the purposes of research with primary care patients, because it limits the opportunity for investigators to examine the prevalence and significance of general anxiety symptoms among depressed primary patients, including the effects of such symptoms on physician detection, differential diagnosis, and treatment of depression, as well as patient acceptance of diagnosis and adherence to treatment. Though our results indicate a high prevalence of past and current anxiety disorders among depressed primary care patients, they undoubtedly underestimate the extent to which the depressed patients are also characterized by considerable anxiety. Studies of de- pressed psychiatric patients suggest that panic disorders, phobias, and obsessive-compulsive disorders predict greater subsequent depressive morbidity [42], but there is a lack of data for primary care patients or data relevant to the significance of symptoms of anxiety that would otherwise be sufficient to warrant a diagnosis of GAD. We encourage modification of the SCID for the investigation of this topic, notably eliminating the skipping of the GAD module when a mood disorder is present.

Two separate sets of issues have been raised about the adequacy of DSM-III-R in primary care. The first is that it may fail to allow for the diagnosis of conditions of mild depression or mixed anxiety and depression which may be highly prevalent. Thus the criticism is that it provides too high a threshold for diagnosis of these conditions. Yet, we found that DSM-III-R allowed for identification of a substantial number of depressed persons as having MDD without substantial symptomatology or impairment. Indeed, our results raise questions whether DSM-III-R criteria are too lenient when applied in an unmodified form to a primary care population. Furthermore, DSM-III-R allows for the diagnosis of additional patients with few depressive symptoms as having an adjustment disorder with depressed mood or mixed emotional features. Depressed mood, tearfulness, or feelings of hopelessness in reaction to an identifiable is sufficient for such a diagnosis if the symptoms are judged to be in excess of a normal reaction or if they interfere with everyday life. In our sample, such adjustment reactions had a weighted prevalence of $4.2 \%$ and accounted for a fifth of the depressive disorders.

On the other hand, it is possible that our use of DSM-III-R criteria still failed to provide a diagnosis for patients who have intermittent periods of mood disturbances that meet neither the requirement of a 2-week duration needed for MDD nor the absence of 2-month periods without symptoms required for a diagnosis of dysthymia. It is also possible that our application of DSM-III-R failed to give diagnoses to substantial numbers of patients who had mixed anxiety-depression states, but who did not have a sufficient number of symptoms specific to either an anxiety or depressive disorder to get any diagnosis [13,43]. The DSM-IV Draft Criteria [44] proposes giving a diagnosis of Anxiety Disorder NOS to such patients, and ICD-9-CM recognizes anxiety depression. Given the high rate of comorbid anxiety disorders among patients who were diagnosed with MDD, it is conceivable that 
some patients with mixed anxiety and depression were not given a diagnosis even though their lives were impaired by their combination of symptoms. This must remain a matter of speculation. The structure of the SCID is such that if patients fail to give a positive answer to questions concerning mood disturbances, other depressive symptoms are not assessed.

The second set of issues about the application of DSM-III-R in primary care concerns the validity of findings for categories whose validity is based on research that has mainly been conducted with psychiatric populations. There are only limited data concerning the validity of psychiatric diagnoses in primary care [16]. In contrast to DSM-III-R, the next revision of the DSM incorporates impairment criteria for major depression [44]. In order to be diagnosed with major depression, a patient must suffer significant distress or impairment in social or occupational functioning in addition to meeting symptom criteria. Application of such a rule would undoubtedly have lowered the estimate of the prevalence of depression in the present sample, but the criteria are imprecise and their validity and clinical utility will need to be specifically demonstrated with primary care patients. In the absence of significant distress, differences in the level of role responsibilities faced by these patients, including their employment status, would influence whether they showed the social impairment needed for a diagnosis of depression. These contextual factors might determine diagnosis among mildly symptomatic patients without validly predicting differential response to treatment. Furthermore, even if the revised criteria would dictate that a considerable proportion of the mildly depressed patients found in the present study would no longer be diagnosed as MDD, there is still the question of how primary care physicians should manage them. At the minimum, the existence of such a group of mildly depressed patients highlights the nature of the challenges facing primary care physicians attempting to adhere to practice guidelines in their efforts to detect, diagnose, and treat depression effectively.

A diagnosis of MDD has generally been shown to be a valid indicator of appropriateness for treatment with antidepressant medication or brief, structured psychotherapies in psychiatric populations [45]. Given the large number of studies comparing antidepressant medication to a placebo, it has been estimated that the probability that antidepressant medication is no more effective than a placebo for MDD is less than $10^{-31}$ [46]. However, the National Institute of Mental Health Collaborative Study [45] found that differences between active treatments and placebo in a 16-week treatment trial were not significant for patients having Hamilton scores less than 21, and that would include most of the depressed patients in the present study. Limited studies with depressed patients drawn from primary care have demonstrated effectiveness for both antidepressants and psychotherapy, but there are few randomized treatment studies, and they tend to be methodologically inadequate [47]. One study found a superiority of amitriptyline to placebo in a sample of relatively mildly depressed, general practice patients [48]. However, this superiority was limited to patients with initial Hamilton scores of 13 or above, and many of the depressed patients in this sample would not meet that minimal severity criterion. Thus, the mildness of the DSM-III-R major depression found in the present sample highlights the need for more treatment outcome studies with representative samples of depressed primary care patients.

Because results presented in this paper are limited to a single two-stage screening and structured interview, they cannot provide definitive answers as to the significance of the relative mildness of the depression that was found. There is a need for a longitudinal perspective in order to ascertain the extent to which this mildness variously represents an inherently mild and self-limiting condition or the early or late stages of more serious episodes of depression. Similarly, these results do not address the extent to which intervention would be acceptable or efficacious with these patients or the extent to which the more mild depression represents vulnerability to subsequent episodes. It has been suggested that persons with mild and even subsyndromal depressive symptoms may be at risk for more severe depression and thus suitable for preventive psychosocial intervention [49], but the benefits of such interventions with primary care patients remain to be demonstrated. It might also be suggested that physicians adopt a strategy of "watchful waiting" with such patients [50], but this would be counter to AHCPR practice guidelines calling for active treatment of patients meeting criteria for major depression.

This research was supported by R01MH43796 from the National Institute of Mental Health 


\section{References}

1. Shapiro S, Skinner EA, Kessler LG, et al: Utilization of health and mental health services: three Epidemiologic Catchment Area sites. Arch Gen Psychiatry 41:971-978, 1984

2. Coyne JC, Fechner-Bates S, Schwenk TL: Nondetection of depression by primary care physicians reconsidered (in press)

3. Gerber PD, Barrett J, Barrett J, et al: Recognition of depression by internists in primary care: a comparison of internist and "gold standard" psychiatric assessments. J Gen Intern Med 4:7-13, 1989

4. Von Korff M, Shapiro S, Burke JD, et al: Anxiety and depression in a primary care clinic: comparison of diagnostic interview schedule, general health questionnaire, and practitioner assessments. Arch Gen Psychiatry 44:152-156, 1987

5. Perez-Stable EJ, Miranda J, Munoz RF, Ying YW: Depression in medical outpatients: underrecognition and misdiagnosis. Arch Intern Med 150:10831088,1990

6. Weissman MM: Advances in psychiatric epidemiology: rates and risks for depression. Am J Public Health 77:445-451, 1987

7. Katon W, Schulberg H: Epidemiology of depression in primary care. Gen Hosp Psychiatry 14:237-247, 1992

8. Coulehan JL, Schulberg HC, Block MR, Janosky JE, Arena VC: Medical co-morbidity of major depressive disorder in a primary medical practice. Arch Intern Med 150:2363-2367, 1990

9. Schulberg HC, Saul M, McClelland M, Ganguli M, Christy W, Frank R: Assessing depression in primary medical and psychiatric practices. Arch Gen Psychiatry 42:1164-1170, 1985

10. Zich JM, Attkisson CC, Greenfield TK: Screening for depression in primary care clinics: the CES-D and the BDL. Int J Psychiatry Med 20:259-277, 1990

11. Hoeper EW, Nycz GR, Cleary PD, Regier DA, Goldberg ID: Estimated prevalence of RDC mental disorder in primary medical care. Int J Ment Health 8:615,1979

12. Blacker CVR, Clare AW: Depressive disorder in primary care. Br J Psychiatry 150:737-751, 1987

13. Barrett JE, Barrett JA, Oxman TE, Gerber PD: The prevalence of psychiatric disorders in a primary care practice. Arch Gen Psychiatry 45:1100-1106, 1988

14. Ormel J, van den Brink W, Koeter MW, et al: Recognition, management, and outcome of psychological disorders in primary care: a naturalistic followup study. Psychol Med 20:909-923, 1990

15. Regier DA, Boyd JH, Birk JD, et al: One-month prevalence of mental disorders in the United States. Based on five Epidemiologic Catchment Area sites. Arch Gen Psychiatry 45:977-986, 1988

16. Smith GR: Developing guidelines for treating depressive disorders in the primary care setting. Gen Hosp Psychiatry 14:228-229, 1992

17. Goldberg DP: The concept of a "case" in general practice. Soc Psychiatry 17:61-65, 1982
18. Johnson DAW, Mellor V: The severity of depression in patients treated in general practice. I Royal College Gen Pract 237:419-422, 1977

19. Sireling LI, Paykel ES, Freeling P, Rao BM, Patel SP. Depression in general practice: case thresholds and diagnosis. Br J Psychiatry 147:113-119, 1985

20. Radloff LS: The CES-D Scale: a self-report depression scale for research in the general population. Appl Psychol Meas 1:385-401, 1977

21. Spitzer RL, Williams JB, Gibbon M, First MB: Struc tured Clinical Interview for DSM-III-R. New York, Biometrics Research Department, New York State Psychiatric Institute, 1989

22. Dohrenwend BP, Shrout PE: Toward the development of a two-stage procedure for case identification in psychiatric epidemiology. In Simmons $R$ (ed), Research in Community and Mental Health. Greenwich, Conn, JAI Press, 1981, pp 295-323

23. Myers JK, Weissman MM: Use of a self-report symptom scale to detect depression in a community sample. Am J Psychiatry 137:1081-1084, 1980

24. Newman SC, Shrout PE, Bland RC: The efficiency of two-phase designs in prevalence surveys of mental disorders. Psychol Med 20:183-193, 1990

25. Endicott J, Spitzer RL: A diagnostic interview: the Schedule for Affective Disorders and Schizophrenia. Arch Gen Psychiatry 35:837-844, 1978

26. Spitzer RL, Endicott J, Robins E: Research Diagnostic Criteria: rational and reliability. Arch Gen Psychiatry 35:773-782, 1978

27. American Psychiatric Association: Diagnostic and statistical manual of mental disorders, 3rd ed (revised). Washington, DC, American Psychiatric Association, 1987

28. Robins LN, Helzer JE, Croughan R, Ratliff KS: National Institute of Mental Health Diagnostic Interview Schedule: its history, characteristics, and validity. Arch Gen Psychiatry 38:837-844, 1981

29. Robins LN: Epidemiology: reflections on testing the validity of psychiatric interviews. Arch Gen Psychiatry 42:918-924, 1985

30. American Psychiatric Association. Diagnostic and Statistical Manual of Mental Disorders, 3rd ed. 1980

31. Von Korff M: Case definitions in primary care: the need for clinical epidemiology. Gen Hosp Psychiatry 14:293-295, 1992

32. Coulehan JL, Schulberg HC, Block MR: The efficiency of depression questionnaires for case finding in primary medical care. J Gen Intern Med 4:541547,1989

33. Fechner-Bates S, Coyne JC, Schwenk TL: The relationship of self-reported distress to depressive disorders and other psychopathology (in press)

34. Coyne JC: Self-reported distress: analog or ersatz depression? Psychol Bull (in press)

35. Deardorff WW, Funabiki D: A diagnostic caution in screening for depressed college students. Cog Ther Res 9:277-284, 1985

36. Hatzenbuehler LC, Parpal M, Matthews L: Classifying college students as depressed or nondepressed using the Beck Depression Inventory: an empirical analysis. J Con Clin Psychiatry 54:328-333, 1983 
J. C. Coyne et al.

37. Hamilton $\mathrm{M}$ : A rating scale for depression. J Neurol Neurosurg Psychiatry 23:56-62, 1960

38. Williams JB: A structured interview guide for the Hamilton Depression Rating Scale. Arch Gen Psychiatry 45:742-747, 1988

39. Cochran WG: Sampling Techniques, 3rd ed. New York: Wiley, 1977

40. Welch WP, Frank RG, Costello AJ: Missing data in psychiatric research: a solution. Psychol Bull 94:177180, 1983

41. Coyne JC, Schwenk TL, Smolinski M: Recognizing depression: a comparison of physician ratings, selfreport, and interview measures. J Am Board Fam Pract 4:207-215, 1991

42. Coryell W, Endicott J, Winokur G: Anxiety syndromes as epiphenomena of primary major depression: outcome and familial psychopathology. Am J Psychiatry 149:100-107, 1992

43. Schulberg HC: Mental disorders in the primary care setting. Research priorities for the 1990's. Gen Hosp Psychiatry 13:156-164, 1991

44. American Psychiatric Association. DSM-IV Draft
Criteria. Washington, DC, American Psychiatric Press, 1993

45. Elkin I, Shea MT, Watkins JT: National Institute of Mental Health Treatment of Depression Collaborative Research Program. Arch Gen Psychiatry 46:971982, 1989

46. Noll K, Davis JM, DeLeon-Jones F: Medication and somatic treatment of depression. In Beckham EE, Leber WR (eds), Handbook of Depression. Homewood, IL, The Dorsey Press, 1985

47. Schulberg HC, Block MR, Coulehan JL: Treating depression in primary care practice: an application of decision analysis. Gen Hosp Psychiatry 11:208-215, 1989

48. Paykel ES, Hollyman JA, Freeling P, Sedgwick P: Predictors of therapeutic benefit from amitriptyline in mild depression: a general practice placebocontrolled trial. J Affective Dis 14:83-95, 1988

49. Klerman GL, Weissman MM: The course, morbidity, and costs of depression. Arch Gen Psychiatry 49:831-834, 1992

50. Freedman DX: Editorial note (especially for the media). Arch Gen Psychiatry 46:983, 1989 